
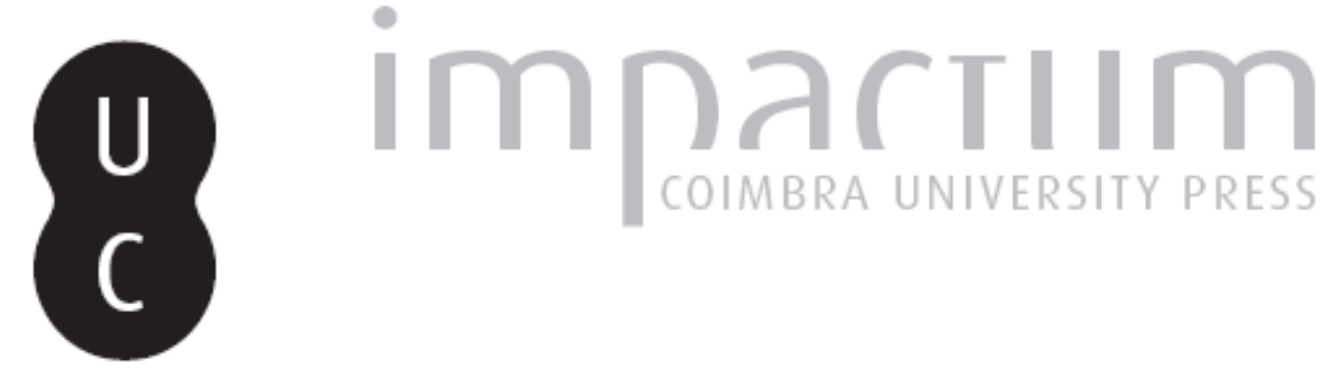

\title{
Planeamento e artificialização dos solos na Área Metropolitana de Lisboa (1990- 2007): conformidade e transgressão da decisão municipal
}

Autor(es): $\quad$ Padeiro, Miguel

Publicado por: Imprensa da Universidade de Coimbra

URL persistente:

URI:http://hdl.handle.net/10316.2/36888

DOI:

DOI:http://dx.doi.org/10.14195/0871-1623_33_8

Accessed : $\quad$ 26-Apr-2023 01:35:36

A navegação consulta e descarregamento dos títulos inseridos nas Bibliotecas Digitais UC Digitalis, UC Pombalina e UC Impactum, pressupõem a aceitação plena e sem reservas dos Termos e Condições de Uso destas Bibliotecas Digitais, disponíveis em https://digitalis.uc.pt/pt-pt/termos.

Conforme exposto nos referidos Termos e Condições de Uso, o descarregamento de títulos de acesso restrito requer uma licença válida de autorização devendo o utilizador aceder ao(s) documento(s) a partir de um endereço de IP da instituição detentora da supramencionada licença.

Ao utilizador é apenas permitido o descarregamento para uso pessoal, pelo que o emprego do(s) título(s) descarregado(s) para outro fim, designadamente comercial, carece de autorização do respetivo autor ou editor da obra.

Na medida em que todas as obras da UC Digitalis se encontram protegidas pelo Código do Direito de Autor e Direitos Conexos e demais legislação aplicável, toda a cópia, parcial ou total, deste documento, nos casos em que é legalmente admitida, deverá conter ou fazer-se acompanhar por este aviso.

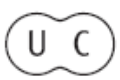




\section{Cadernos de Geografia}
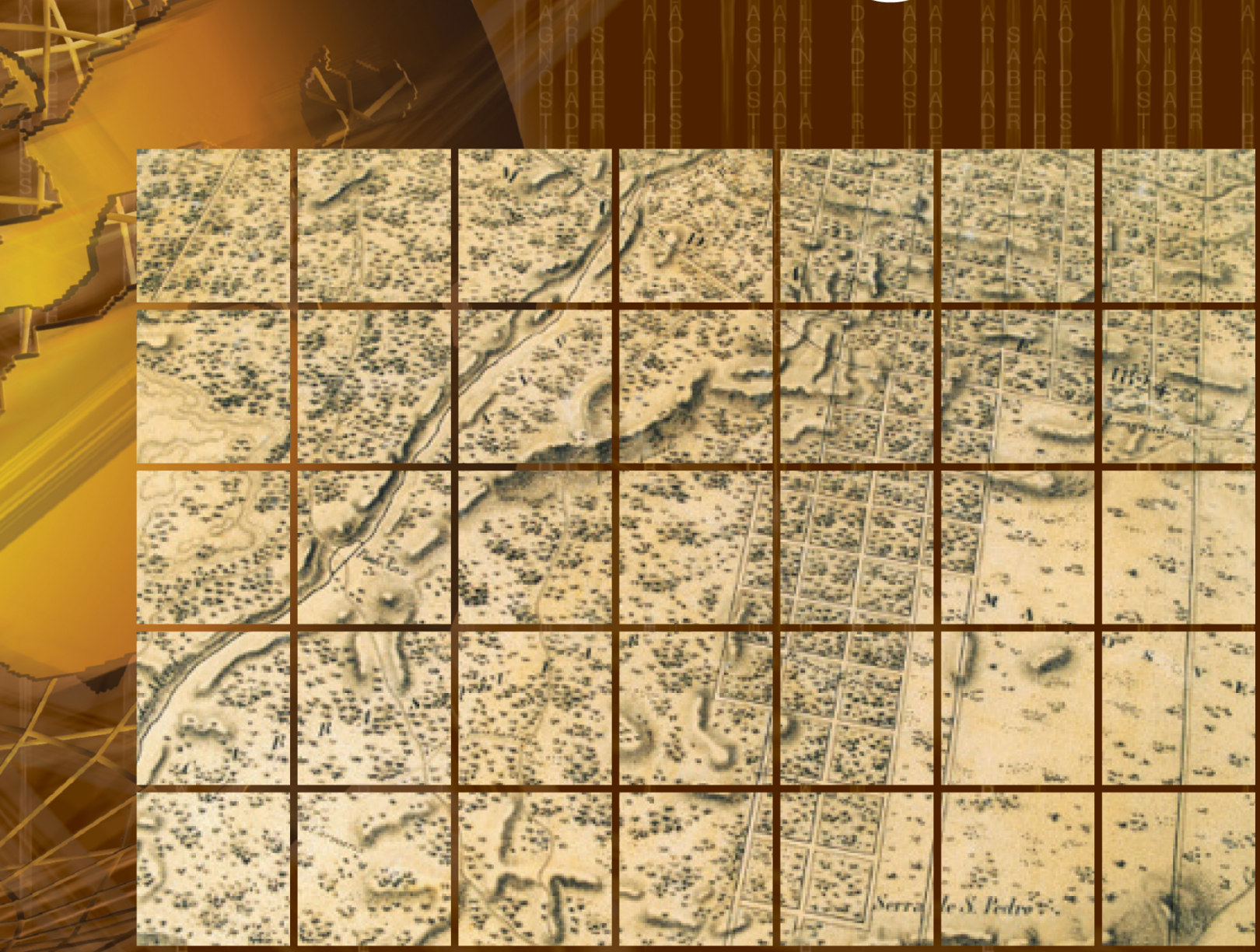

№ 33 - 2014

Imprensa da Universidade de Coimbra Faculdade de Letras | Universidade de Coimbra 


\title{
Planeamento e artificialização dos solos na Área Metropolitana de Lisboa (1990-2007): conformidade e transgressão da decisão municipal Planning and artificialization of soils in the Lisbon Metropolitan Area (1990- -2007): conformity and transgression of municipal decision
}

\author{
Miguel Padeiro \\ CEG - IGOT - Universidade de Lisboa. \\ jmpadeiro@campus.ul.pt
}

\section{Resumo:}

A conversão de áreas agrícolas e naturais para usos urbanos nas margens das cidades tornou-se nos últimos anos um tema incontornável das políticas territoriais. Este artigo analisa o papel dos Planos Directores Municipais na evolução da ocupação do solo no período 1990-2007 na Área Metropolitana de Lisboa, a partir de um balanço da conformidade da evolução dos solos relativamente aos usos previstos pelo planeamento. Mostra-se que as conversões dos usos efectivas foram superiores ao previsto, que o grau de conformidade da execução dos planos apresenta uma distribuição geográfica relacionada com a pressão urbana existente, e que as trangressões ocorrem, quer dentro ou fora dos perímetros de protecção de usos natural e agrícola.

Palavras-chave: Ocupação do solo. Artificialização. Planeamento territorial. Crescimento urbano.

\section{Abstract:}

Over the last years, the conversion of agricultural and natural land in periurban areas has become a prominent topic for territorial policies. This paper analyses the role of Municipal Master Plans in the evolution of land use between 1990 and 2007 in the Lisbon Metropolitan Area. It is based on a conformity analysis of the actual evolution compared with the initial plans. Results show that: i) there were more land use conversions than previously planned; ii) the geographical distribution of conformance degree is clearly related to the existing urban pressure; iii) nationwide preservation regime has not hampered transgression.

Keywords: Land use. Artificialisation. Spatial planning. Urban growth. 
Introdução

A regulação do crescimento espacial representa um dos desafios mais importantes e abrangentes das políticas urbanas, pela multiplicidade de problemáticas envolvidas e pela complexidade das interacções entre uma e outras. Em Portugal, a urbanização relativamente recente e de carácter quase explosivo, fruto de um processo democrático e de integração europeia tardios, reflectiu- se numa capacidade limitada das autoridades públicas em conter o crescimento e a fragmentação das manchas urbanas ao sabor das oportunidades fundiárias (Domingues, 2006), facilitando deste modo uma expansão geralmente considerada excessiva.

As políticas europeias e nacionais (Agenda 21, Horizonte 2020, PNPOT - Programa Nacional da Política de Ordenamento do Território, ENDS - Estratégia Nacional de Desenvolvimento Sustentável, para citar apenas estas) têm vindo a promover modelos territoriais e de planeamento susceptíveis de enquadrar o crescimento urbano. Se a abordagem mais recente, exemplificada pelo Plano Regional de Ordenamento do Território da Área Metropolitana de Lisboa (PROT-AML), se encontra baseada em perspectivas estratégicas mais flexíveis (PEREIRA e Nunes da Silva, 2008), o zonamento urbano e o princípio de subsidiariedade têm mantido os actores locais e, em particular, os municípios, numa posição privilegiada. No caso português, o Plano Director Municipal (PDM) constitui a figura incontornável do planeamento e das políticas territoriais, apesar das críticas à volta da sua execução parcial, da falta de fiscalização e da postura geralmente expansionista que apresentou na década de 1990 (CATITA, 2009).

Se bem que este artigo efectue um balanço da artificialização no período 1990-2007, o objectivo consiste sobretudo em avaliar quantitativamente o papel dos PDM no cumprimento dos objectivos traçados e aprovados pelas Câmaras Municipais, tanto em termos de urbanização (definição de áreas urbanizáveis) como em termos de preservação de uso não urbano. Tendo como foco as áreas identificadas como "naturais" e "agrícolas", procura-se averiguar o grau de conformidade da execução dos planos: este enfoque é particularmente importante na medida em que muito se tem escrito acerca do sobredimensionamento das áreas urbanizáveis, e muito menos a respeito das áreas a preservar.

Com este objectivo em mente, será em primeiro lugar efectuada uma revisão da literatura, com especial destaque para a problemática da artificialização dos solos em contexto de expansão urbana e para o papel e obstáculos do planeamento municipal (1). Será abordada a metodologia do estudo (2), seguindo-se a apresentação dos resultados, primeiro em termos de trajectórias das unidades espaciais no período 1990-2007 (3), introduzindo-se depois o papel dos PDM na realização ou desrespeito das evoluções planeadas (4).

\section{Planeamento e conversão de solos na AML}

\subsection{Factores e desafios da conversão de solos}

Como objectivos assumidos das políticas territoriais, a regulação dos solos e a protecção dos espaços periféricos têm acompanhado a expansão urbana - embora geralmente com algum atraso - tendo-se tornado um tema fundamental da agenda institucional e científica a nível mundial. Razões de ordem estética, funcional e sócio-cultural constituiram o motor da evolução da retórica da contenção urbana: o receio de um declínio dos centros e, em paralelo, a (re)valorização dos mesmos, o surgimento das questões ambientais na agenda política relacionadas com o consumo de solo, as emissões de gases e poluentes e a dependência energética, os custos colectivos da expansão, relacionados com as redes e equipamentos, o custo social da fragmentação que geralmente marca os territórios das margens urbanas, mas também a reacção ao espectro indesejado da cidade norte-americana (WILLIAMs et al., 2000) levaram ao ressurgimento de um discurso desfavorável à expansão e à emergência de políticas de conservação das paisagens de cariz natural e/ou agrícola (Koomen et al., 2008), herdeiras das políticas de Green Belts (FreY, 2000). Neste contexto, a conversão de solos anteriormente agrícolas ou naturais em redor dos aglomerados urbanos para usos urbanos levanta questões relacionadas com as suas causas e com os modos e margem de manobra da sua regulação à escala macro/meso.

Pode-se distinguir três categorias de factores da conversão de solos agrícolas e naturais (MAzzocCH et al., 2013). Os factores endógenos incluem as características demográficas dos agricultores, a evolução (fragmentação, concentração) da estrutura fundiária, e os mecanismos económicos que regem o valor das rendas agrícolas e dos terrenos (MAzzoccH et al., 2013). A dinâmica urbana constitui o segundo grupo: estrutura económica e internacionalização da economia, grau de marginalização da actividade agrícola, dinâmica demográfica do aglomerado urbano, factores técnicos (infra-estruturas). Por fim, o contexto político e institucional condiciona o próprio sistema de planeamento, a distribuição vertical (do supra-nacional ao local) e horizontal (sectorial) das competências em matéria de controlo e regulação dos solos, bem como as interacções entre actores em jogo (ABRANTEs et al., 2013b; PADEIRo, 2014).

Assim sendo, a preservação de áreas naturais e agrícolas em redor dos grandes aglomerados urbanos implica a elaboração de medidas complexas de gestão e restrição do crescimento das manchas urbanas ("growth management"). Além de incentivos fiscais e da transferência dos direitos de urbanização, o zonamento tem sido a abordagem mais usada pelas entidades públicas, ora com as já mencionadas Green Belts, ora através do estabelecimento de áreas, exclusivas ou flexíveis, dedicadas a usos não urbanos e apresentando, contudo, alguns inconvenientes. Os efeitos perversos constituem o primeiro deles: aumento dos preços fundiários devido à diminuição da área cons- 
trutiva e do número de proprietários (DAwkins e NeLSON, 2002), transferência da pressão urbana para zonas limítrofes não abrangidas pela protecção (Koomen et al., 2008). Além disso colocam-se questões institucionais: a falta de implementação relacionada com o grau de maturidade do sistema de planeamento e o peso do princípio de subsidiariedade e dos localismos. Associados à frequente impotência (ou inexistência) dos órgãos regionais, este último tem sido apontado como um factor desfavorável ao controlo efectivo da expansão urbana (Pereira e Nunes dA SiLva, 2008). No fundo, a redução do consumo de solos consegue-se principalmente onde existe um regime mais restritivo, uma política de regulação dos solos mais antiga, mais bem assente e vinculativa a nível local (PAULSEN, 2013).

\subsection{Na AML, a periferização, o planeamento e a conversão de solos}

O caso da Área Metropolitana de Lisboa (AML) é paradigmático de um contexto de crescimento populacional e expansão espacial pouco controlados até à década de 90 . O forte crescimento populacional registado a partir dos anos de 1950, a internacionalização da economia, principalmente após a entrada na então CEE, as políticas favoráveis à propriedade individual (GuerRa, 2011) e ao automóvel (PAdeIRo, 2012a; Nunes dA Silva, 2013), a financiarização recente do mercado imobiliário europeu cujos contornos, em Portugal, ainda carecem de uma análise aprofundada, a predominância das lógicas privadas e neo-liberais em matéria de investimentos com impactos territoriais directos (Alves, 2012), e por fim a própria lei das finanças locais que estimula a construção, contribuiram para o considerável aumento da área artificializada (CAETANo et al., 2005) que, associado a uma extrema fragmentação territorial, tem gerado disfunções urbanas de difícil resolução (Domingues, 2006; Ferrão, 2010; Portas et al., 2011).

Esta evolução está intimamente ligada à dificuldade das entidades públicas em regular e orientar o crescimento urbano. Num contexto de grande imaturidade democrática e de inexperiência em matéria de planeamento urbanístico, a principal figura do plano, o PDM, surgiu discretamente em 1982 para finalmente se impor na década seguinte perante a ausência de outros instrumentos orientadores de âmbito nacional ou regional (AlvEs et al., 1993). O surgimento tardio destes últimos não chegou a dar origem a uma adaptação dos PDM. As políticas sectoriais de preservação de espaços agrícolas e naturais, embora com maior tradição em Portugal (RIBEIRo e BARÃo, 2006), também têm esbarrado nas suas próprias incoerências em termos de delimitação e nos pedidos de suspensão parcial por parte dos municípios, por motivos de interesse económico (Pardal, 2004; Galvão, 2008). As tendências recentes, marcadas por uma maior conflitualidade no que respeita à ocupação do espaço, derivam em parte dessas dificuldades, da relativa opacidade dos processos e decisões, e dos novos modos de acção territorial, envolvendo uma grande diversidade de intervenientes. As tentativas de convergência das orientações do or- denamento e das políticas territoriais, nos vários níveis de competências (níveis nacional, regional, local), continuam deste modo a suscitar algumas reservas quanto à efectividade da aplicação local das grandes orientações de nível superior.

Não se procura aqui determinar os factores da artificialização dos solos ou da decisão de reafectação pelos municípios (PADEIRO, 2014), mas antes avaliar a relação entre os usos do solo previstos pelos PDM da década de 1990 (conversão de solos, permanência dos usos) e a evolução verificada depois da aprovação dos PDM. Três hipóteses centrais são objecto da presente análise. A primeira sugere que a intensa artificialização de solos na região de Lisboa resulta das próprias decisões municipais, desfavoráveis à preservação dos espaços abertos não artificializados. Neste caso, haveria tendência expansiva já nos instrumentos do planeamento local - o que corresponde às observações habituais. A segunda consiste em que a conversão de solos efectiva pode não reflectir os PDM, traduzindo-se por um elevado grau de inconformidade que convém quantificar. A terceira é de que a conversão de solos ocorre também em locais sob regime de protecção especial de âmbito nacional (RAN, REN e outros regimes de protecção). De acordo com esta hipótese, as medidas de protecção poderão ter um efeito limitado, assistindo-se então à transgressão de áreas de preservação dos usos agrícolas e naturais. Relacionada com esta segunda hipótese surge uma questão: as áreas protegidas de âmbito nacional apresentarão maior resistência à conversão de solos do que as áreas de uso não urbano estabelecidas no âmbito dos PDM?

\section{A abordagem em termos de conformidade e transgressão}

\subsection{Conformidade e transgressão dos usos previamente estabelecidos}

A avaliação das decisões do planeamento municipal constitui uma fase indissociável e algo esquecida do processo de planeamento (OliveIRa e PINHo, 2009). A ausência de instrumentos, dados e/ou metodologias adequadas limita a avaliação a quantificações gerais das áreas urbanizadas, agrícolas e naturais sem comparação com o previsto pelo plano. A esta dificuldade juntam-se as divergências quanto à interpretação das evoluções, de acordo com a posição do observador e com os interesses subjacentes, e o uso da avaliação como instrumento de legitimação do poder. No fundo, a reformulação dos planos, derivada das avaliações colectivas negociadas e da necessária adaptação às novas realidades traduz-se frequentemente pela simples adopção de planos que não procuram corrigir o que falhou no plano anterior, constituindo apenas uma actualização do mesmo com dados mais recentes.

Uma possível abordagem consiste na análise em termos de conformidade entre o planeamento e 
a evolução real, que tem vindo a ganhar relevância nos últimos anos (LoH, 2011). Não escapa a alguns problemas relacionados com o horizonte temporal ideal da avaliação, sendo eles próprios debatidos na esfera política (BAER, 1997), com a natureza e significado das inconformidades, nomeadamente a distinção entre o que advém da variação normal entre o planeado e a realidade, e o que surge de verdadeiros problemas do planeamento, e com a evolução do pensamento urbanístico: como referem Koomen et al. (2008), seguir um plano de maneira rigorosa pode vir a ser considerado, anos mais tarde, como um erro de planeamento e sobretudo uma falta de adaptação às novas exigências e correntes de pensamento. Ainda assim, a perspectiva da avaliação de conformidade traz inegáveis vantagens, nomeadamente a clareza dos indicadores que a assemelham a uma avaliação ex-post, bem como a pertinência de usar como base de avaliação o plano tal como foi pensado e aprovado. A expectativa dos planificadores é de que o plano venha a ter incidência directa na evolução futura e real da ocupação do solo: uma inconformidade entre o plano e a realidade denuncia uma falha do plano, independentemente da natureza e causa da mesma (LAURIAN et al., 2004). A análise em termos de conformidade justifica-se, portanto, enquanto instrumento de avaliação da influência do planeamento institucional sobre o porvir da ocupação dos solos e, logo, como instrumento de apoio ao planeamento.

\subsection{Dados e metodologia}

Várias fontes estatísticas e cartográficas foram utilizadas na realização deste estudo: i) a Carta de Ocupação do Solo de 1990 (COS-1990), baseada no tratamento de imagens satélite de 1985-1987; ii) a Carta de Ocupação do Solo de 2007 (COS-2007); iii) a informação cartográfica vectorial das Reservas Agrícola e Ecológica Nacionais, bem como de outras modalidades de protecção do espaço natural (Sítios Naturais, Zonas de Protecção Especial, Áreas Protegidas); iv) a informação cartográfica vectorial dos Planos Directores Municipais (PDM) aprovados entre 1992 e 1999. Destes últimos foram extraídas as áreas consideradas urbanizáveis, naturais, agrícolas, urbanas e dedicadas exclusivamente a actividades económicas. Foram retiradas todas as unidades espaciais não abrangidas pela COS-1990 ou com uso desconhecido $\left(180 \mathrm{~km}^{2}\right)$ - essencialmente nos concelhos de Sintra e Mafra.

A sobreposição das camadas de informação cartográfica permitiu obter unidades espaciais ad hoc através do recorte de cada unidade de acordo com a ocupação do solo em 1990 e em 2007, com o uso previsto no PDM e a inclusão, se for o caso, numa área protegida de âmbito regional ou nacional. Um desafio inerente a este tipo de método de sobreposição de camadas de origens diversas reside na coerência da informação obtida, uma vez que a nomenclatura dos usos dos PDM não só varia entre as municipalidades como também apresenta algumas diferenças em relação à COS. No caso da heterogeneidade intermunicipal, procedeu-se à construção de uma nomenclatura ad hoc, com vista à sua unificação: foram obtidas seis categorias de usos (agrícola, natural, urbano existente, actividade económica existente, expansão, equipamentos, outros), tendo cada categoria um número reduzido de sub- categorias (para mais detalhes, ver PADEIRO, 2012b). No caso das diferenças com à COS, as resoluções espaciais semelhantes $(1: 25.000)$ e as categorias de usos relativamente próximas ("solo artificializado" da COS-2007 e "área urbana" ou "urbanizável" do PDM, por exemplo) permitem a sobreposição, desde que não se entre num nível de pormenor demasiado elevado (densidades, sub-categorias).

0 método desenvolve-se em duas fases. Em primeiro lugar analisam-se as trajectórias das unidades espaciais em termos de ocupação do solo entre 1990 e 2007, com particular atenção na evolução dos espaços identificados na COS-1990 como de cariz natural ou agrícola ${ }^{1}$. Em segundo lugar é dado enfoque à relação entre as evoluções registadas e às decisões de afectação dos solos tomadas através dos PDM nos anos de 1990. Os resultados são agregados à escala da AML Norte e AML Sul (separadas pelo rio Tejo), podendo também ser desagregados ao nível dos municípios e freguesias.

\section{Trajectórias da ocupação do solo (1990-2007)}

O balanço da evolução da ocupação do solo entre 1990 e 2007 na AML (excluindo áreas não abrangidas pela COS-1990 ou de uso desconhecido) encontra-se de acordo com as observações já efectuadas por outros autores (CAETANo et al., 2005) (Quadro I). 0 espaço natural perdeu 7,4\% da superfície a Norte do Tejo, 5,2\% a Sul. A diminuição das áreas agrícolas foi mais acentuada: $-14,4 \%$ na $A M L$ Norte e $-6,5 \%$ na Península de Setúbal. Esta diferença relativa entre áreas naturais e agrícolas pode explicar-se pelo facto de as áreas naturais terem menor probabilidade de ser convertidas do que as áreas agrícolas, resultado não só do declínio generalizado da agricultura como actividade empregadora na Europa ocidental, mas também de políticas de conservação da natureza geralmente mais amplas e maduras do que as políticas de preservação das funções agrícolas em torno das cidades, que só nos últimos anos ganharam alguma relevância. Este movimento corresponde, por sinal, à inversão de uma tendência histórica de transformação de áreas naturais para ocupação agrícola (Koomen et al., 2008). Paralelo óbvio da diminuição geral de áreas naturais e agrícolas, o aumento da superfície artificializada é considerável nas duas margens: $+42,2 \%$ a Norte, $+52,2 \%$ a Sul.

\footnotetext{
A definição de "natural" e "agrícola" baseia-se, neste texto e por razões metodológicas, na classificação da Carta de Ocupação do Solo. É portanto determinada, ao contrário dos conceitos mais amplos da geografia, pelo único critério de uso do solo: "meios semi-naturais" e "floresta" no caso do solo natural; "área agrícola" e "espaço agro-florestal" no caso da agricultura (COS-1990 e COS-2007)
} 
Quadro I

Evolução da ocupação do solo na AML (1990-2007).

\begin{tabular}{|c|c|c|c|c|c|c|}
\hline \multirow{2}{*}{ Tipos de espaço } & \multicolumn{3}{|c|}{ AML Norte } & \multicolumn{3}{c|}{ AML Sul } \\
\cline { 2 - 7 } & $\begin{array}{c}\text { Área } \\
\left(\mathbf{k m}^{2}\right) \\
\text { em } \\
1990\end{array}$ & $\begin{array}{c}\text { Área } \\
\left(\mathbf{k m}^{2}\right) \\
\text { em } \\
2007\end{array}$ & $\begin{array}{c}\text { Evolução } \\
1990- \\
-2007 \\
(\%)\end{array}$ & $\begin{array}{c}\text { Área } \\
\left(\mathbf{k m}^{2}\right) \\
\text { em } \\
1990\end{array}$ & $\begin{array}{c}\text { Área } \\
\left(\mathbf{k m}^{2}\right) \\
\text { em } \\
2007\end{array}$ & $\begin{array}{c}\text { Evolução } \\
1990- \\
-2007 \\
(\%)\end{array}$ \\
\hline $\begin{array}{c}\text { Espaço natural } \\
\text { total }\end{array}$ & 418 & 387 & $-7,4 \%$ & 714 & 677 & $-5,2 \%$ \\
\hline $\begin{array}{c}\text { Espaço agrícola } \\
\text { total }\end{array}$ & 480 & 411 & $-14,4 \%$ & 586 & 548 & $-6,5 \%$ \\
\hline $\begin{array}{c}\text { Espaço } \\
\text { urbanizado }\end{array}$ & 244 & 347 & $+42,2 \%$ & 157 & 239 & $+52,2 \%$ \\
\hline $\begin{array}{c}\text { Espaço natural } \\
\text { ou agrícola da } \\
\text { RAN e/ou REN }\end{array}$ & 500 & 487 & $-2,6 \%$ & 442 & 432 & $-2,3 \%$ \\
\hline $\begin{array}{c}\text { Total da área } \\
\text { analisada }\end{array}$ & 1168,4 & - & 1543,9 & - \\
\hline
\end{tabular}

Fontes: COS-1990, COS-2007, cálculos próprios. Foram excluídas as áreas identificadas na COS-1990 como KK9 (não abrangidas ou de uso desconhecido). Os dados da COS não distinguem os solos em regime de protecção.

No que respeita à artificialização dos solos classificados em 1990 como "naturais" ou "agrícolas” (Quadro II), são notórios três factos. Em primeiro lugar, nota-se uma importante artificialização dos solos não protegidos por reservas, abrangendo $14,8 \%$ da área natural e $16,1 \%$ da área agrícola no conjunto da $\mathrm{AML}^{2}$. Em segundo lugar, é notável o efeito da RAN e da REN: a conversão de solos naturais e agrícolas protegidos pelas reservas nacionais (RAN, REN) não foi totalmente impedida mas travada de forma significativa, registando perdas abaixo de 5\%: em números absolutos, $31,4 \mathrm{~km}^{2}$ de áreas sob regime de protecção foram artificializadas no conjunto da AML, contra $230 \mathrm{~km}^{2}$ de áreas não protegidas por reservas nacionais. Uma leitura menos "optimista" reparará contudo que cerca de $15 \%$ da artificialização de áreas naturais teve lugar em áreas de REN, e que $9 \%$ da artificialização de áreas agrícolas ocorreu em áreas de RAN - o que não representa uma área marginal tendo em conta os objectivos assumidos pelas autoridades públicas através das medidas de protecção. Por fim, uma nítida diferenciação entre as duas margens do Tejo (AML Norte e a AML Sul) aparece a dois níveis. Por um lado, as áreas naturais tendem a desaparecer mais do que as agrícolas a Norte, enquanto que a Sul desaparece mais área agrícola do que natural, o que tende a reforçar uma diferença pré-existente com um Norte mais agrícola e um Sul onde as áreas naturais predominam. Por outro, a Grande Lisboa regista globalmente mais conversões $(16,6 \%$ das áreas agrícolas ou naturais) do que a Margem Sul $(8,5 \%)$ - uma evolução que a proximidade de Lisboa acentua mas que poderá vir a inverter-se de acordo com o objectivo, constante do Plano Regional de Ordenamento do Território da AML (PROT-AML), de reequilíbrio das áreas urbanizadas entre as duas margens do rio Tejo.
Quadro II

Artificialização de solos “naturais” e “agrícolas” (1990-2007).

\begin{tabular}{|c|c|c|c|c|c|c|}
\hline \multirow[b]{2}{*}{ Áreas em km² } & \multicolumn{6}{|c|}{ Tipos de ocupação do solo } \\
\hline & $\begin{array}{l}\text { Natural } \\
\text { não REN }\end{array}$ & $\begin{array}{l}\text { Agrícola } \\
\text { não RAN }\end{array}$ & $\begin{array}{l}\text { Natural } \\
\text { da REN }\end{array}$ & $\begin{array}{c}\text { Agrícola } \\
\text { da RAN }\end{array}$ & $\begin{array}{c}\text { Total } \\
\text { Natural }\end{array}$ & \begin{tabular}{|c|} 
Total \\
Agrícola
\end{tabular} \\
\hline \multicolumn{7}{|c|}{ 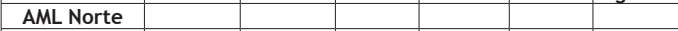 } \\
\hline Total 1990 & 221,1 & 284,6 & 197,8 & 196,3 & 418,9 & 480,9 \\
\hline Total 2007 & 201,5 & 180,3 & 185,7 & 230,7 & 387,2 & 411,0 \\
\hline \begin{tabular}{|c|} 
Área \\
artificializada
\end{tabular} & 64,8 & 64,5 & 13,8 & 6,7 & 78,6 & 71,2 \\
\hline $\begin{array}{c}\text { \% (do total } \\
1990)\end{array}$ & $29,3 \%$ & $22,7 \%$ & $7,0 \%$ & $3,4 \%$ & $18,8 \%$ & $14,8 \%$ \\
\hline \multicolumn{7}{|l|}{ AML Sul } \\
\hline Total 1990 & 510,8 & 473,7 & 204,0 & 113,1 & 714,8 & 586,8 \\
\hline Total 2007 & 454,5 & 451,3 & 223,3 & 97,5 & 677,8 & 548,8 \\
\hline $\begin{array}{c}\text { Área } \\
\text { artificializada }\end{array}$ & 43,3 & 57,4 & 5,5 & 5,4 & 48,8 & 62,8 \\
\hline $\begin{array}{c}\text { \% (do total } \\
1990)\end{array}$ & $8,5 \%$ & $12,1 \%$ & $2,7 \%$ & $4,8 \%$ & $6,8 \%$ & $10,7 \%$ \\
\hline
\end{tabular}

Fontes: COS-1990, COS-2007, cálculos próprios

Este primeiro conjunto de observações permite desde já constatar a influência - imperfeita - de algumas medidas de limitação da artificialização na AML. Permite também apreender o elevado ritmo de urbanização que tem marcado a região nas últimas duas décadas. Embora se conheça a tendência expansiva dos PDM da década de 1990, revela-se necessário aprofundar a análise através do papel dos mesmos e, em particular, do seu grau de execução num horizonte de dez a quinze anos.

\section{Conformidade: realidade versus planeamento}

Como já foi referido, o objectivo central deste artigo consiste em questionar o papel e grau de execução dos PDM em termos de artificialização de solos inicialmente classificados como naturais ou agrícolas. É reconhecido que as políticas locais têm evidenciado uma postura bastante expansiva, concedendo a largas áreas dos respectivos territórios uma função de expansão urbana - uma observação ainda válida no que respeita às mais recentes revisões (Pereira e Nunes da Silva, 2008; Carranca e Castro, 2011). No conjunto da AML, as áreas de expansão estabelecidas pelos PDM representam perto de $2 / 3$ da superfície ocupada por áreas já artificializadas, e o rácio entre áreas de expansão e áreas já urbanizadas atinge em média 0,46 , podendo chegar a 0,98 ou 1 , como em Alcochete e Setúbal, o que vem duplicar a área urbana potencial (PADEIRO, 2012b). Uma execução rigorosa e completa dos planos significaria nesta estrita perspectiva uma expansão urbana importante, o que já não corresponde aos objectivos assumidos pelas estratégias europeias (Horizonte 2020, Carta de Leipzig), nacionais (PNPOT, ENDS) e metropolitanas (PROT-AML). Convém no entanto averiguar o grau de conformidade da execução dos planos, no sentido de avaliar o seu desempenho próprio.

\subsection{Tendência expansiva dos municípios da AML}

De facto, os PDM da AML apresentam uma tendência generalizada para a expansão urbana. As 
áreas de expansão representavam um aumento potencial de $42 \%$ (na AML Norte) e 69\% (na AML Sul) da área artificializada existente identificada na COS-1990 (Quadro III). Estas áreas de expansão abrangem um total de $240 \mathrm{~km}^{2}$, quando a área já artificializada atingia $360 \mathrm{~km}^{2}$ em 1990 .

\subsection{Aproveitar as áreas urbanizáveis transgredir as decisões de protecção}

Com efeito, cada unidade espacial seguiu no período 1990-2007 uma trajectória específica de acordo com a sua classificação na COS-1990, no

Quadro III

Afectação dos solos nos PDM e relação com os usos identificados na COS-1990

\begin{tabular}{|c|c|c|c|c|c|c|c|}
\hline \multirow{2}{*}{ Áreas em km² Afectação dos solos nos PDM } & \multicolumn{3}{|c|}{ Afectação dos solos tendo em conta a categoria na COS-1990 } \\
\cline { 2 - 7 } & $\begin{array}{c}\text { Espaço urbano } \\
\text { (EU) }\end{array}$ & $\begin{array}{c}\text { Espaço de activi- } \\
\text { dades económicas } \\
\text { (AA) }\end{array}$ & $\begin{array}{c}\text { Áreas de ex- } \\
\text { pansão (EE) }\end{array}$ & Rácio EE / (EU+AA) & $\begin{array}{c}\text { Áreas de expansão } \\
\text { em espaço natural }\end{array}$ & $\begin{array}{c}\text { Áreas de expansão } \\
\text { em espaço agrícola }\end{array}$ & $\begin{array}{c}\text { Áreas de expansão } \\
\text { em espaço agrícola } \\
\text { ou natural }\end{array}$ \\
\hline AML Norte & 217,6 & 41,8 & 109,9 & 0,42 & $44,7(10,7 \%)$ & $39,1(8,1 \%)$ & 83,8 \\
\hline AML Sul & 143,2 & 46,0 & 130,7 & 0,69 & $53,9(7,5 \%)$ & $62,5(10,7 \%)$ & 116,4 \\
\hline Total & 360,8 & 87,8 & 240,6 & 0,54 & $98,6(8,7 \%)$ & $101,6(9,5 \%)$ & 200,2 \\
\hline
\end{tabular}

Fontes: PDM, COS-1990, cálculos próprios

Confrontando a afectação das unidades espaciais com a sua categoria de uso na COS-1990, verifica-se que, no conjunto da AML, cerca de $10 \%$ do espaço natural e agrícola foi considerado como área de expansão dos tecidos urbanos nos PDM. Como atrás foi visto, a proporção desses espaços efectivamente convertida no período 1990-2007 é ligeiramente maior no caso da AML Norte (18 e 15\%), sendo a diferença mais ténue a Sul (7 a $11 \%$ ). Dito de outra forma, perspectiva-se uma tendência para um maior descontrolo a Norte do Tejo do que a Sul das decisões municipais - embora a realidade tenha de ser averiguada através das localizações e não apenas da quantificação das áreas, podendo ocorrer uma discrepância geográfica entre o planeado e o realizado. Tal pode ser efectuado a partir da análise da trajectória das unidades espaciais, que permite saber se a conversão do uso do solo numa determinada parcela corresponde ao que foi planeado ou se pelo contrário constitui uma transgressão da decisão municipal.
PDM e na COS-2007 (Figura 1). A quantificação das áreas que seguiram cada uma das trajectórias possíveis permite esboçar, num determinado território (freguesia, concelho, $\mathrm{AML}$ ), um balanço da conformidade das evoluções posteriores à aprovação dos PDM.

As quatro trajectórias definidas (aproveitamento e respeito pela ocupação inicial como trajectórias de conformidade, não aproveitamento e transgressão como trajectórias de inconformidade) são avaliadas quantitativamente de duas formas. Em primeiro lugar, comparam-se as áreas que seguiram cada uma das quatro trajectórias possíveis. Em segundo lugar, calcula-se uma taxa de aproveitamento e uma taxa de transgressão, ambas relativas a um determinado território:

Ocupação do solo 1990

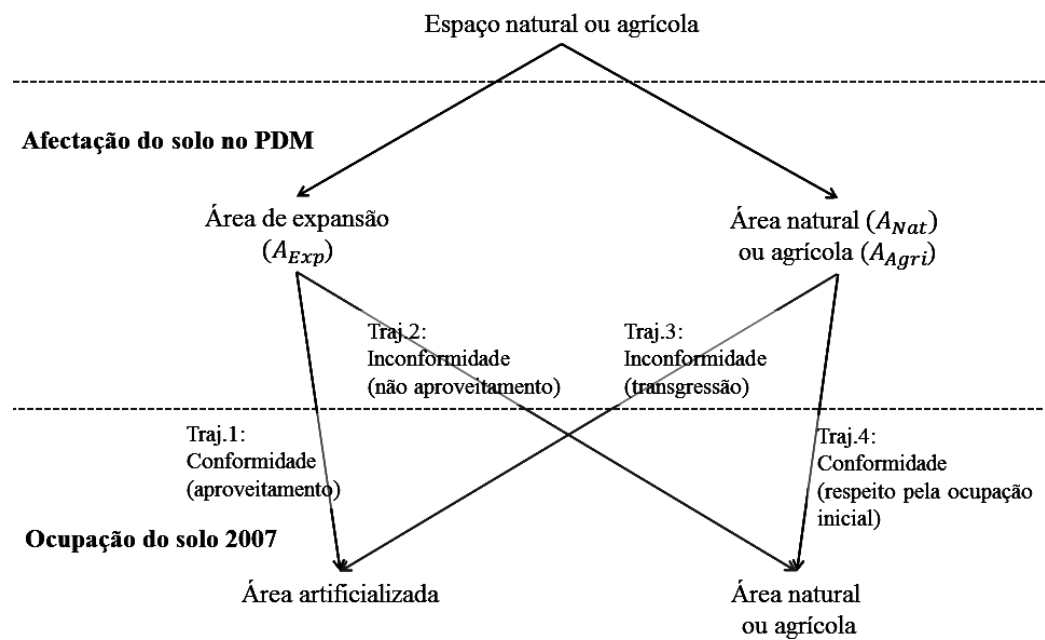

Figura 1

Trajectórias da ocupação e planeamento do solo. 


$$
\begin{gathered}
T_{A p}=\frac{A_{\text {Traj } 1}}{A_{\text {Exp }}} \\
T_{T r}=\frac{A_{\text {Traj } 3}}{\left(A_{\text {Agri }}+A_{\text {Nat }}\right)}
\end{gathered}
$$

onde: $A_{\text {Traj1 }}$ corresponde à área que seguiu a trajectória 1 (artificialização entre a aprovação do PDM e 2007 de um local classificado como área de expansão), $A_{\text {Exp }}$ é a área de expansão, $A_{\text {Traj3 }}$ a área que seguiu a trajectória 3 (artificialização num local classificado como agrícola ou natural no PDM), $A_{\text {Agri }}$ a área agrícola no PDM, $A_{\text {Nat }}$ a área natural no PDM.

Em terceiro lugar comparam-se as áreas de não aproveitamento com as áreas de transgressão: parte destas últimas (áreas urbanizadas em locais não previstos para o efeito) poderiam - teoricamente - ter sido afectadas àquelas (áreas urbanizáveis que se mantiveram no estado inicial), evidenciando deste modo a necessidade de uma política de redistribuição dos usos do solo, eventualmente supra-municipal - ou pelo menos maior execução do plano. Para este efeito pode-se calcular um simples rácio entre as áreas de transgressão e as áreas não aproveitadas.

Os resultados indicam que os níveis de inconformidade (trajectórias 2 e 3 ) se situam à volta de $10 \%$ do total das trajectórias possíveis (Quadro IV): $10,1 \%$ a Norte do Tejo, $8,4 \%$ a Sul, totalizando cerca de $200 \mathrm{~km}^{2}$ no conjunto da AML. Cerca de 30 (a Sul) a 45\% (a Norte) dessas inconformidades foram transgressões, sendo as restantes constituídas por falta de aproveitamento de áreas de expansão (não artificializadas). A Norte, a área usada para transgressão serviria para preencher a quase totalidade da área de expansão que acabou por não ser artificializada - o que o rácio entre as áreas de transgressão e as áreas não aproveitadas $(0,84)$ ilustra nitidamente (Quadro V). A Sul do Tejo, seria um pouco menos de metade da mesma, com $76 \mathrm{~km}^{2}$ não aproveitados e $32 \mathrm{~km}^{2}$ de áreas transgredidas.

Quadro IV

Trajectória de conversão ou conservação dos espaços naturais e

\begin{tabular}{|c|c|c|c|c|c|c|c|}
\hline \multirow[b]{2}{*}{$\begin{array}{c}\text { Áreas } \\
\text { geográ- } \\
\text { ficas }\end{array}$} & \multicolumn{7}{|c|}{ Tipos de ocupação do solo } \\
\hline & $\begin{array}{l}\text { Espaço } \\
\text { natu- } \\
\text { ral ou } \\
\text { agrícola } \\
\text { (COS-90) }\end{array}$ & $\begin{array}{l}A_{E \times p} \\
(\mathrm{PDM})\end{array}$ & $\begin{array}{c}\text { Área } \\
\text { Traj. } \\
1\end{array}$ & $\begin{array}{c}\text { Área } \\
\text { Traj. } \\
2\end{array}$ & $\begin{array}{c}A_{\text {Nat }} \text { e } A_{\text {Agri }} \\
(\text { PDM) }\end{array}$ & $\begin{array}{c}\text { Área } \\
\text { Traj. } \\
3\end{array}$ & $\begin{array}{l}\text { Área } \\
\text { Traj. } 4\end{array}$ \\
\hline $\begin{array}{c}\text { AML } \\
\text { Norte }\end{array}$ & 899,7 & 83,9 & 34,1 & 49,3 & 671,5 & 41,3 & 619,5 \\
\hline AML Sul & 1259,7 & 99,7 & 32,2 & 67,3 & 1017,2 & 31,5 & 979,5 \\
\hline TOTAL & 2159,3 & 183,6 & 66,3 & 116,6 & 1688,7 & 72,8 & 1599,1 \\
\hline
\end{tabular}
agrícolas (1990-PDM-2007).

Fontes: COS-1990, PDM, COS-2007, cálculos próprios. Traj. 1: conformidade (aproveitamento); Traj. 2: inconformidade (não aproveitamento); Traj. 3: inconformidade (transgressão); Traj. 4: conformidade (respeito da ocupação inicial). As áreas são todas expressas em $\mathrm{km}^{2}$.
Quadro V

Aproveitamento e transgressão

\begin{tabular}{|c|c|c|c|c|}
\hline $\begin{array}{c}\text { Áreas } \\
\text { geográfi- } \\
\text { cas }\end{array}$ & $\begin{array}{c}\text { Proporção de } \\
\text { área natural/ } \\
\text { agrícola artifi- } \\
\text { cializada }\end{array}$ & $\begin{array}{c}\text { Taxa de } \\
\text { aprovei- } \\
\text { tamento }\end{array}$ & $\begin{array}{c}\text { Taxa de } \\
\text { trans- } \\
\text { gressão }\end{array}$ & $\begin{array}{c}\text { Rácio áreas de } \\
\text { transgressão } \\
\text { / áreas não } \\
\text { aproveitadas }\end{array}$ \\
\hline $\begin{array}{c}\text { AML } \\
\text { Norte }\end{array}$ & $8,4 \%$ & $40,6 \%$ & $6,2 \%$ & 0,838 \\
\hline AML Sul & $5,1 \%$ & $32,3 \%$ & $3,1 \%$ & 0,467 \\
\hline TOTAL & $6,4 \%$ & $36,1 \%$ & $4,3 \%$ & 0,624 \\
\hline
\end{tabular}

Fontes: COS-1990, PDM, COS-2007, cálculos próprios.

No geral, a taxa de transgressão é relativamente baixa, situando-se em cerca de 3 a $6 \%$. A reduzida taxa de aproveitamento sugere o carácter excessivo e a ausência de fundamentos (em termos quantitativos) para justificar as transgressões ocorridas e vem confirmar, ao mesmo tempo, que a fragmentação e dispersão das áreas artificializadas são um resultado do estabelecimento de áreas desproporcionadas para urbanização (Gonçalves, 2009; PoRTAS et al., 2011).

Olhando para as áreas sob regime de protecção, a transgressão de áreas de preservação através de reservas nacionais (RAN, REN), de Sítios Protegidos, Zonas de Protecção Especial ou Áreas Protegidas é relativamente limitada no conjunto da AML, situando-se contudo pouco abaixo da transgressão sem regime de protecção (Quadro $\mathrm{VI}$ ): 4,6\% na AML Norte, $3,1 \%$ na AML Sul. Neste último caso, encontra-se ao mesmo nível que a transgressão ocorrida fora das áreas sob regime de protecção, o que vem demonstrar a pouca eficiência do enquadramento legal comparativamente com as áreas não protegidas.

Quadro VI

Transgressão de áreas agrícolas e naturais protegidas a nível regional e nacional.

\begin{tabular}{|c|c|c|c|c|}
\hline & $\begin{array}{c}\text { Área agrícola/na- } \\
\text { tural (PDM) sem } \\
\text { outra protecção } \\
\text { de âmbito nacio- } \\
\text { nal ou regional }\end{array}$ & $\begin{array}{c}\text { Área agrícola/na- } \\
\text { tural (PDM) com } \\
\text { outra protecção } \\
\text { de âmbito nacio- } \\
\text { nal ou regional }\end{array}$ & $\begin{array}{c}\text { Trans- } \\
\text { gressão } \\
\text { de áreas } \\
\text { com pro- } \\
\text { tecção }\end{array}$ & $\begin{array}{c}\text { Taxa de } \\
\text { transgres- } \\
\text { são de } \\
\text { áreas com } \\
\text { protecção }\end{array}$ \\
\hline AML Norte & 186,3 & 485,2 & 22,1 & $4,6 \%$ \\
\hline AML Sul & 526,7 & 506,8 & 15,5 & $3,1 \%$ \\
\hline TOTAL & 713,0 & 992,0 & 37,7 & $3,8 \%$ \\
\hline
\end{tabular}

Fontes: COS-1990, COS-2007, cálculos próprios. Áreas expressas em $\mathrm{km}^{2}$. São consideradas apenas as áreas identificadas na COS-1990 como agrícolas ou naturais.

\section{3. À escala local, o efeito da pressão urbana}

A desagregação dos resultados por concelho permite tecer duas observações. A primeira (Quadro VII, Figura 2) é de que a inconformidade da realidade em relação aos planos tem especial incidência na primeira coroa da região de Lisboa: Odivelas, Amadora e Oeiras na Margem Norte (entre 33 e 40\% das trajectórias possíveis), Barreiro, Seixal e Almada na Margem Sul (de 30 a 46\%). O grau de inconformidade apresenta uma clara ligação com a distância em relação à capital. Ainda assim, convém distinguir a natureza da inconformidade, que pode ser constituída por transgressão ou por falta de aproveitamento: esta poderá 
não ser tão estigmatizada, à luz dos objectivos inscritos na agenda política europeia e nacional, como aquela. A transgressão é de facto praticamente residual, comparada com a falta de aproveitamento, em Almada e no Barreiro, mas representa quase metade da inconformidade no conjunto da AML, mais de metade em seis concelhos, mais de um terço em doze concelhos. Lisboa, Mafra, Vila Franca de Xira e Alcochete são os municípios que maior peso da transgressão apresentam no conjunto da inconformidade entre plano e execução - mas neste grupo apenas Lisboa tem uma taxa de inconformidade elevada $(27,9 \%)$.

Quadro VII

Trajectórias por concelho na AML.

\begin{tabular}{|c|c|c|c|c|c|c|}
\hline Concelhos & $\begin{array}{c}\text { Área } \\
\text { Traj. } \\
1\end{array}$ & $\begin{array}{c}\text { Área } \\
\text { Traj. } \\
2\end{array}$ & $\begin{array}{c}\text { Área } \\
\text { Traj. } \\
3\end{array}$ & $\begin{array}{c}\text { Área } \\
\text { Traj. } \\
4\end{array}$ & $\begin{array}{c}\text { Taxa de } \\
\text { inconfor- } \\
\text { midade }\end{array}$ & $\begin{array}{c}\text { \% da transgres- } \\
\text { são na inconfor- } \\
\text { midade total }\end{array}$ \\
\hline Alcochete & 1,6 & 2,2 & 3,6 & 74,3 & $7,0 \%$ & $62,3 \%$ \\
\hline Almada & 7,5 & 9,2 & 0,9 & 15,2 & $30,7 \%$ & $8,7 \%$ \\
\hline Amadora & 1,2 & 1,5 & 1,6 & 4,2 & $36,2 \%$ & $51,7 \%$ \\
\hline Barreiro & 1,4 & 4,9 & 0,2 & 4,5 & $46,5 \%$ & $3,7 \%$ \\
\hline Cascais & 6,0 & 5,4 & 2,6 & 29,4 & $18,5 \%$ & $32,8 \%$ \\
\hline Lisboa & 0,8 & 0,3 & 0,8 & 2,0 & $27,9 \%$ & $71,3 \%$ \\
\hline Loures & 4,5 & 10,5 & 6,1 & 94,9 & $14,3 \%$ & $36,7 \%$ \\
\hline Mafra & 4,1 & 5,1 & 10,6 & 156,2 & $8,9 \%$ & $67,5 \%$ \\
\hline Moita & 1,0 & 2,3 & 1,8 & 17,0 & $18,8 \%$ & $44,2 \%$ \\
\hline $\begin{array}{c}\text { Montijo } \\
\text { Este }\end{array}$ & 0,5 & 2,6 & 2,8 & 244,2 & $2,2 \%$ & $52,2 \%$ \\
\hline $\begin{array}{c}\text { Montijo } \\
\text { Oeste }\end{array}$ & 1,0 & 3,0 & 2,8 & 20,1 & $21,5 \%$ & $47,6 \%$ \\
\hline Odivelas & 2,1 & 3,6 & 0,5 & 4,4 & $39,1 \%$ & $13,0 \%$ \\
\hline Oeiras & 4,4 & 4,3 & 1,6 & 7,2 & $33,8 \%$ & $27,5 \%$ \\
\hline Palmela & 6,0 & 16,4 & 10,6 & 365,0 & $6,8 \%$ & $39,3 \%$ \\
\hline Seixal & 6,8 & 13,7 & 3,3 & 23,2 & $36,2 \%$ & $19,3 \%$ \\
\hline Sesimbra & 5,3 & 4,5 & 3,0 & 141,2 & $4,9 \%$ & $39,8 \%$ \\
\hline Setúbal & 8,6 & 17,6 & 3,4 & 90,1 & $17,5 \%$ & $16,0 \%$ \\
\hline Sintra & 8,7 & 14,8 & 10,1 & 119,5 & $16,3 \%$ & $40,5 \%$ \\
\hline VF Xira & 2,2 & 3,9 & 7,4 & 201,8 & $5,5 \%$ & $65,7 \%$ \\
\hline & & & & & \\
\hline
\end{tabular}

Fontes: COS-1990, COS-2007, cálculos próprios. Áreas expressas em km².
A segunda observação relevante é que no conjunto dos concelhos da AML existe uma forte correlação entre a disponibilidade de espaço natural e agrícola e o grau de inconformidade ( $r$ de Pearson $=0,887$ ). É também elevada a correlação entre o espaço natural e agrícola e o nível de transgressão $(r=0,725)$ (Figura 3): quanto menor for a área disponível (e maior, portanto, a área artificializada já existente), maior serão a inconformidade geral e a taxa de transgressão. 0 resultado é muito semelhante se considerarmos a relação entre o nível de inconformidade global (ou apenas transgressão) e a proporção desses espaços agrícola ou natural que os PDM classificaram para manter: quanto maior a área protegida pelo PDM, menor a ocorrência de transgressões $(r=0,677)$. Moderada é a correlação $(r=0,385)$ quando se considera o nível das freguesias - o que é previsível cada vez que se aumenta a escala e consequentemente o número de unidades espaciais do universo analisado. Este resultado não é surpreendente se se considerar que a pressão urbana (e a consequente tendência de conversão de solos) se exerce com mais força nos locais onde existe já uma certa densidade, equipamentos e serviços básicos - mas também poderia ser contra-intuitivo na medida em que maiores densidades podem desempenhar um papel de dissuasão enquanto aumenta a procura de espaços menos povoados (CARRIón-FLORES e IRWIN, 2004), para funções residenciais, eventualmente de residência secundária ou turística como acontece na AML Sul ou nos concelhos de Mafra, Sintra e Cascais.

Os desvios mais importantes em relação à curva logarítmica da Figura 3 são o Barreiro e Almada, com níveis de transgressão abaixo do "previsto" (sendo o Barreiro o único município com valor situado a mais de 2 desvios-padrão do valor predito). Existe uma nítida diferença entre os concelhos

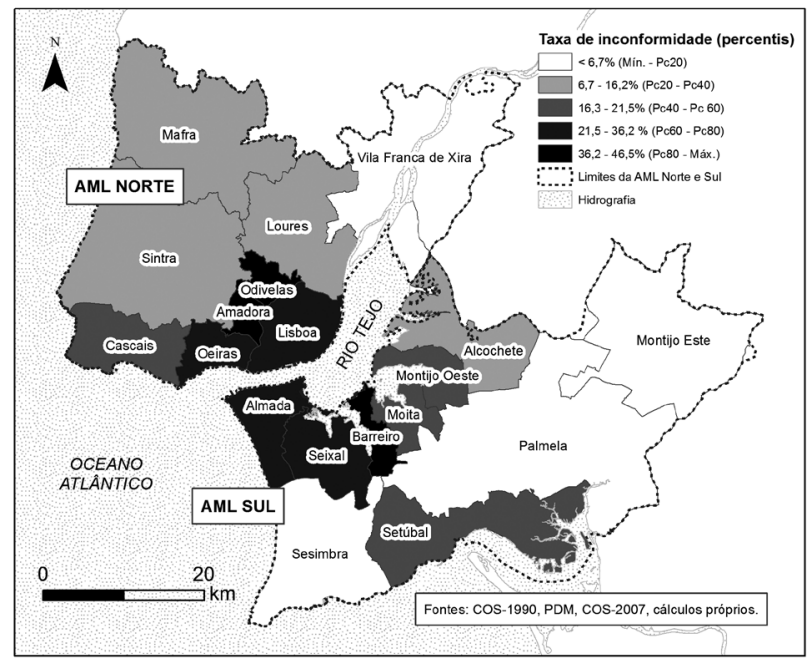

Figura 2

Taxa de inconformidade por concelho na Área Metropolitana de Lisboa. 


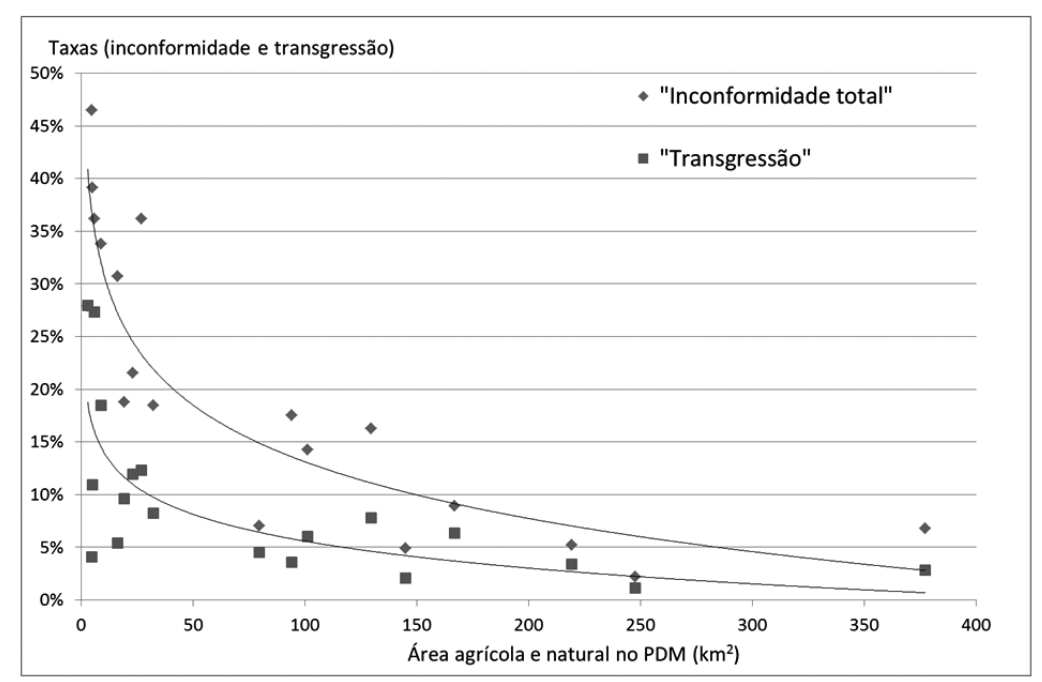

Figura 3

Relação entre a taxa de transgressão e as áreas agrícolas e naturais nos concelhos da AML.

da AML Norte, com níveis de transgressão acima da curva de ajustamento (tirando Cascais e Odivelas, abaixo da curva) e os concelhos da AML Sul, com níveis de transgressão abaixo da curva (tirando Seixal, Montijo Oeste e Palmela): como se viu, a AML Norte apresenta uma taxa de transgressão superior à AML Sul, o que não deriva do peso de alguns poucos concelhos mas de uma situação comum a quase todos os concelhos da AML Norte. Os níveis de transgressão ficam sempre abaixo de $11 \mathrm{~km}^{2}$ (municípios mais extensos). A clivagem Norte/Sul não se mantém, contudo, quando se considera a inconformidade geral. Este duplo resultado, já evocado anteriormente (Quadro V), é a expressão evidente de uma pressão urbana mais intensa a Norte do Tejo, com efeitos em termos de transgres- são de áreas agrícolas e naturais, do que a Sul, onde as dinâmicas locais não atingiram o grau esperado pelos municípios - o que não impediu um certo nível, ainda assim, de transgressão.

A distribuição geográfica das taxas de transgressão ao nível das freguesias aparenta seguir uma estrutura radial (clivagem centro-periferia) alterada por alguns eixos de crescimento privilegiados, nomeadamente as linhas de Cascais e Vila Franca de Xira, bem como a linha de Sintra nas zonas mais próximas de Lisboa (Figura 4). A Norte, Venda do Pinheiro $(18,5 \%)$ e Ericeira $(11,5 \%)$ destacam-se em relação às freguesias vizinhas, sendo as dinâmicas rodoviária e balnear factores evidentes mas não exclusivos. A Sul observa-se uma estrutura radial semelhante (Setúbal à parte), bem como algumas

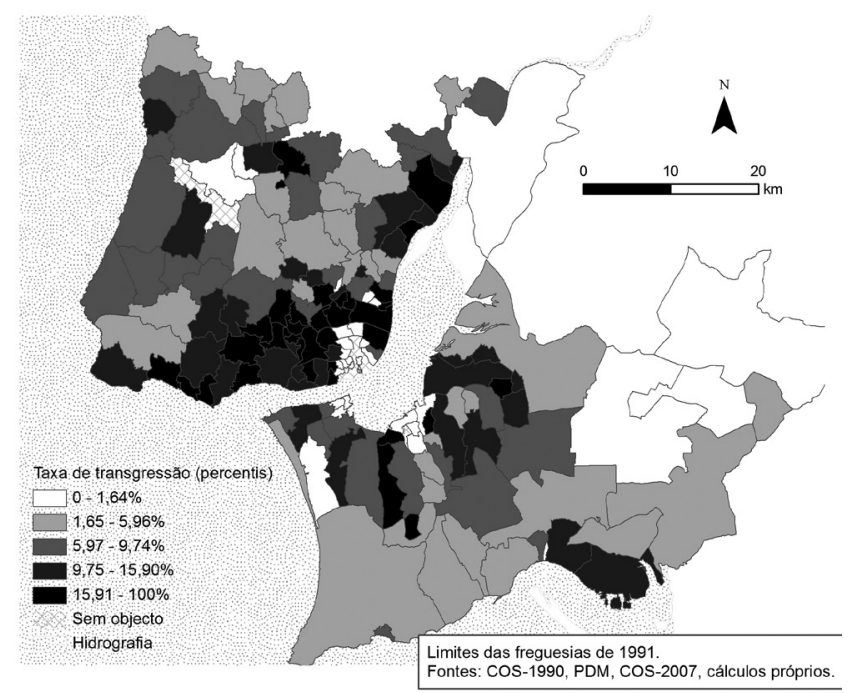

Figura 4

Taxas de transgressão nas freguesias da AML. 
das freguesias mais próximas do Tejo, com tecido urbano consolidado (Barreiro, Lavradio, Cacilhas).

Contudo, as taxas de transgressão correspondem, nalguns casos, a áreas muito reduzidas. Considerando as superfícies, o essencial das áreas agrícolas e naturais transgredidas encontra-se em freguesias periféricas da AML: 21 freguesias, cuja área transgredida é superior a $1 \mathrm{~km}^{2}$, representam $50,2 \%$ da área transgredida total da AML, dominados por Pinhal Novo, Alcochete, Palmela, Sesimbra (Castelo), Mafra e Quinta do Anjo.

\section{Conclusão}

O objectivo inicial deste artigo consistia em avaliar a relação entre os usos do solo previstos pelos PDM da década de 1990 e a evolução verificada entre a sua aprovação e 2007. De uma maneira geral, o nível de conversão de solos agrícolas e naturais real é superior ao nível inicialmente previsto, sobretudo na AML Norte. As reservas (RAN, REN) travaram a conversão de solos - embora se deva reconhecer que ainda assim 10 a $15 \%$ das conversões ocorreram em áreas sob regime de protecção. As mesmas não reduziram significativamente os níveis de transgressão em comparação com áreas não protegidas, o que vem refutar o seu papel na conservação de espaços agrícolas e naturais na AML.

É também notável que a taxa de não aproveitamento de áreas declaradas urbanizáveis tenha sido relativamente elevada, sendo a causa principal da inconformidade. Enquanto se transmitiam alguns sinais de forte pressão urbana, com transgressões a ocorrerem indiscriminadamente em áreas sob regime de protecção ou fora delas, e com conversões a ultrapassarem globalmente o expectado, áreas urbanizáveis em proporção desmesurada ficaram por preencher - um resultado bem conhecido e na origem, juntamente com outros factores, da fragmentação territorial visível no conjunto da AML (DoMINGUES, 2006).

O paralelo entre transgressão de áreas não previstas e não-aproveitamento de áreas de expansão sobredimensionadas apoia-se, no fundo, na tendência recente para o aumento do espaço construído em áreas até então pouco concorridas devido aos regulamentos urbanísticos, e corresponde em simultâneo ao aumento das necessidades de espaço per capita, às possibilidades oferecidas por uma mobilidade individual que se apoia numa rede de infra-estruturas em constante desenvolvimento, e possivelmente ao acesso a lucros maiores derivados da construção em locais não urbanizáveis e, por isso mesmo, mais baratos.

0 relativo descontrolo face a uma pressão urbana, principal força motriz das conversões dos usos, cuja proporção é maior na AML Norte do que na AML Sul, maior no centro do que na periferia, vem confirmar a eficâcia limitada dos instrumentos de planeamento e, principalmente, a ambiguidade dos instrumentos de âmbito supra-municipal. É certo que a natureza e as causas da transgressão, bem como da falta de aproveitamento, podem sujeitar-se a interpretações diversas, primeiro porque subsistem dúvidas quanto aos factores explicativos da menor ou maior tendência para a conversão (ilegítima ou não) de solos, que só uma análise estatística aprofundada poderá resolver, segundo porque cada transgressão tem o seu próprio significado histórico, político, territorial, social e ambiental - que pode variar de acordo com o momento da sua análise e com o actor. Ainda assim, os instrumentos ao dispor falharam no objectivo de reduzir a transgressão de áreas protegidas.

Num contexto de forte tendência para a adopção de medidas de suspensão parcial dos PDM (GALvão, 2008) mas também, mais recentemente, de maior flexibilização e postura estratégica das políticas públicas territoriais, é legítimo questionar a possibilidade de uma maior rigidez no que toca à artificialização de solos: fiscalização supra-municipal, envolvimento de outros níveis de competências em detrimento de um localismo que nesta matéria mostra os seus limites, avaliação a posteriori dos planos e da sua execução.

\section{Bibliografia}

Abrantes, P.; Padeiro, M.; Queirós, M. e Marques da Costa, E. (2013b) - “Lezíria do Tejo : agriculture et étalement urbain aux marges métropolitaines de Lisbonne”. Cahiers Agricultures, 22, pp. 526-534.

Alves, F. B.; Sacadura, F. C. e Vaz, L. C. (1993) - “Planos e planeadores. PDM e Administração Municipal”. Portuguese Society of Urbanists, 5 de Julho de 1993, Lisboa.

Alves, T. (2012) - “Requalificar cidades: do betão aos conteúdos. Tomando sempre novas qualidades". In: JACINTO, R. - A cidade e os novos desafios urbanos, 65-82. Centro de Estudos Ibéricos, Âncora Editora, Guarda, Lisboa, pp. 65-82.

Caetano, M.; Carrão, H. e Painho, M. (2005) - Alterações da ocupação do solo em Portugal Continental: 1985-2000. Instituto do Ambiente, Amadora.

Carranca, M. A. e Castro, N. (2011) - Dinâmica dos perímetros urbanos nos PDM revistos após a publicação do PNPOT

- Fase 1: Análise. DGOTDU, Lisboa.

Carrión-Flores, C. e IrWin, E. G. (2004) - “Determinants of Residential Land-Use Conversion and Sprawl at the Rural-Urban Fringe”. American Journal of Agricultural Economics, 86, pp. 889-904.

Catita, A., (2009) - "A situação actual do sistema de planeamento e gestão territorial: uma nova era, novas responsabilidades". Inforgeo, 2009, pp. 9-15.

Dawkins, C. J. e Nelson, A. C. (2002) - “Urban containment policies and housing prices: an international comparison 
with implications for future research". Land Use Policy, 19, pp. 1-12.

Domingues, A. (Ed.) (2006) - Cidade e democracia: 30 anos de transformação urbana em Portugal. Argumentum, Lisboa.

Ferrão, J. (2010) - Ordenamento do território: 25 anos de aprendizagem, Europa Novas Fronteiras, 2010, pp. 77-84.

FREY, H. W. (2000) - "Not green belts but green wedges: the precarious relationship between city and country". Urban Design International, 2000/5, pp. 13-25.

Galvão, S. (2008) - "Repensar o planeamento local: que soluções para a rigidez das normas dos planos municipais?", Actas do Encontro Anual 2008 Ad Urbem. Ad Urbem, DGOTDU, FCT, Lisboa, pp. 281-296.

Gonçalves, J. (2009) - "Colmatar a deriva urbanística do planeamento municipal: remediação ou oportunidade?", Inforgeo, 2009, pp. 147-157.

Guerra, I. (2011) - "As políticas de habitação em Portugal: à procura de novos caminhos". Cidades, Comunidades

e Territórios, 2011/22, pp. 41-68.

Koomen, E.; Dekkers, J. e van Dijk, T. (2008) - “Open-space preservation in the Netherlands: Planning, practice and prospects". Land Use Policy, 25, pp. 361-377.

Laurian, L.; Day, M.; Berke, P.; Ericksen, N.; Backhurst, M.; Crawford, J. e Dixon, J. (2004) - "Evaluating Plan Implementation: A Conformance-Based Methodology”. Journal of the American Planning Association, 70, pp. 471-480.

LoH, C. G. (2011) - "Assessing and Interpreting Non-conformance in Land-use Planning Implementation". Planning Practice \& Research, 26, pp. 271-287.

Mazzocchi, C.; Salı, G. e Corsi, S. (2013) - "Land use conversion in metropolitan areas and the permanence of agriculture: Sensitivity Index of Agricultural Land (SIAL), a tool for territorial analysis". Land Use Policy, 35, pp. 155-162.
Nunes dA Silva, F. (2013) - "Mobilidade urbana: os desafios do futuro". Cadernos Metrópole, 15, pp. 377-388.

Oliveira, V. e Pinho, P. (2009) - "Evaluating Plans, Processes and Results”. Planning Theory \& Practice, 10, pp. 35-63.

Padeiro, M. (2012a) - "Conciliar os transportes e o ordenamento urbano: avanços recentes e aplicabilidade em áreas metropolitanas portuguesas". Cidades, Comunidades e Territórios, 2012/25, pp. 1-20.

Padeiro, M. (2012b) - "Integrating municipal land use planning with accessibility patterns: expecting (or not?) smarter expansion areas in the Lisbon Region?". RSA European Conference, RSA, Delft (Holanda), pp. 1-19.

PadeIRo, M. (2014) - "The influence of transport infrastructures on land-use conversion decision within municipal plans". Journal of Transport and Land Use, 7, pp. 71-85.

PARDAL, S. (Ed.) (2004) - Estudo sobre o novo diploma para a RAN, REN e disciplina da construção fora dos perímetros urbanos. Instituto Superior de Agronomia, Universidade Técnica de Lisboa, Lisboa.

Paulsen, K. (2013) - "The effects of growth management on the spatial extent of urban development, revisited". Land Economics, 89, pp. 193-210.

Pereira, M. e Nunes da Silva, F. (2008) - "Modelos de ordenamento em confronto na área metropolitana de Lisboa: cidade alargada ou recentragem metropolitana?" Cadernos Metrópole, 2008, pp. 107-123.

Portas, N.; Domingues, Á. e Cabral, J. (2011) -Políticas urbanas II: transformações, regulação e projectos. FCG, Lisboa.

RIBEIRo, L. e BARÃo, T. (2006) - "Greenways for recreation and maintenance of landscape quality: five case studies in Portugal". Landscape and Urban Planning, 76, pp. 79-97.

Williams, K.; Burton, E. e Jenks, M. (Eds.) (2000) - Achieving sustainable urban forms. E\&FN Spon, Londres. 